\title{
National Healthcare Safety Network (NHSN) Report, data summary for 2006, issued June 2007
}

Jonathan R. Edwards, MS, Kelly D. Peterson, BBA, Mary L. Andrus, BA, RN, CIC, James S. Tolson, BS, Joy S. Goulding, Margaret A. Dudeck, MPH, Randy B. Mincey, BA, Daniel A. Pollock, MD, Teresa C. Horan, MPH, and the NHSN Facilities Atlanta, Georgia

This report is a summary of device-associated infections data collected and reported by hospitals participating in the National Healthcare Safety Network (NHSN) from January through December 2006. This report updates previously published data from the National Nosocomial Infections Surveillance (NNIS) system. ${ }^{1-3}$

The NHSN was established in 2005 to integrate and supersede 3 legacy surveillance systems at the Centers for Disease Control and Prevention (CDC): the NNIS system, the Dialysis Surveillance Network (DSN), and the National Surveillance of Healthcare Workers (NaSH). Similar to the NNIS system, NHSN facilities voluntarily report their healthcare-associated infection (HAI) surveillance data for aggregation into a single national database for the following purposes:

- Estimation of the magnitude of HAI;

- discovery of HAI trends;

- facilitation of inter - and intrahospital comparisons with risk-adjusted data that can be used for local quality improvement activities; and

- assistance for facilities in developing surveillance and analysis methods that permit timely recognition of patient safety problems and prompt intervention with appropriate measures.

\footnotetext{
From the Division of Healthcare Quality Promotion, National Center for Preparedness, Detection and Control of Infectious Diseases, Centers for Disease Control and Prevention, Public Health Service, US Department of Health and Human Services, Atlanta, GA.

Address correspondence to Jonathan R. Edwards, MS, Centers for Disease Control and Prevention, Mailstop A-24, Atlanta, GA 30333.

The findings and conclusions of the report are those of the authors and do not necessarily represent the views of the Centers for Disease Control and Prevention.

Am J Infect Control 2007;35:290-30I

0196-6553/\$0.00

This is a US government work. There are no restrictions on its use. doi:10.1016/j.ajic.2007.04.001
}

Identity of all NHSN facilities is held confidential in accordance with Sections 304, 306, and 308(d) of the Public Health Service Act (42 USC 242b, 242K, and $242 \mathrm{~m}(\mathrm{~d}))$.

\section{METHODS}

The NHSN has both a Patient Safety and a Healthcare Personnel Safety surveillance component. Within the Patient Safety component, the data are collected using standardized methods and definitions and are grouped into specific module protocols ${ }^{4,5}$ as follows:

- Device-associated module: See section below.

- Procedure-associated module: Facilities choose to monitor in- or outpatients undergoing selected operative procedures for the presence of surgical site infection or postprocedure pneumonia.

- Medication-associated module: For certain locations, facilities choose to report susceptibility data for selected organisms and/or antimicrobial-use data for selected agents.

The modules may be used singly or simultaneously, but, once selected, they must be used for a minimum of 1 calendar month. All infections are categorized using standard CDC definitions that include laboratory and clinical criteria. ${ }^{5}$ Although the Device-associated module may also be used by facilities other than hospitals, including outpatient dialysis centers, this first report focuses only on Device-associated module data reported by hospitals. A report of data from this module for outpatient dialysis centers will be published separately. Data from the Procedure-associated module will be included in a subsequent NHSN Report when sufficient data are available. Data from the Medication-associated module will be published in a separate report.

Device-associated (DA) module: Infection control professionals (ICPs) may choose to collect data on central line-associated primary bloodstream infections, 
Table I. NHSN hospitals contributing data used in this report

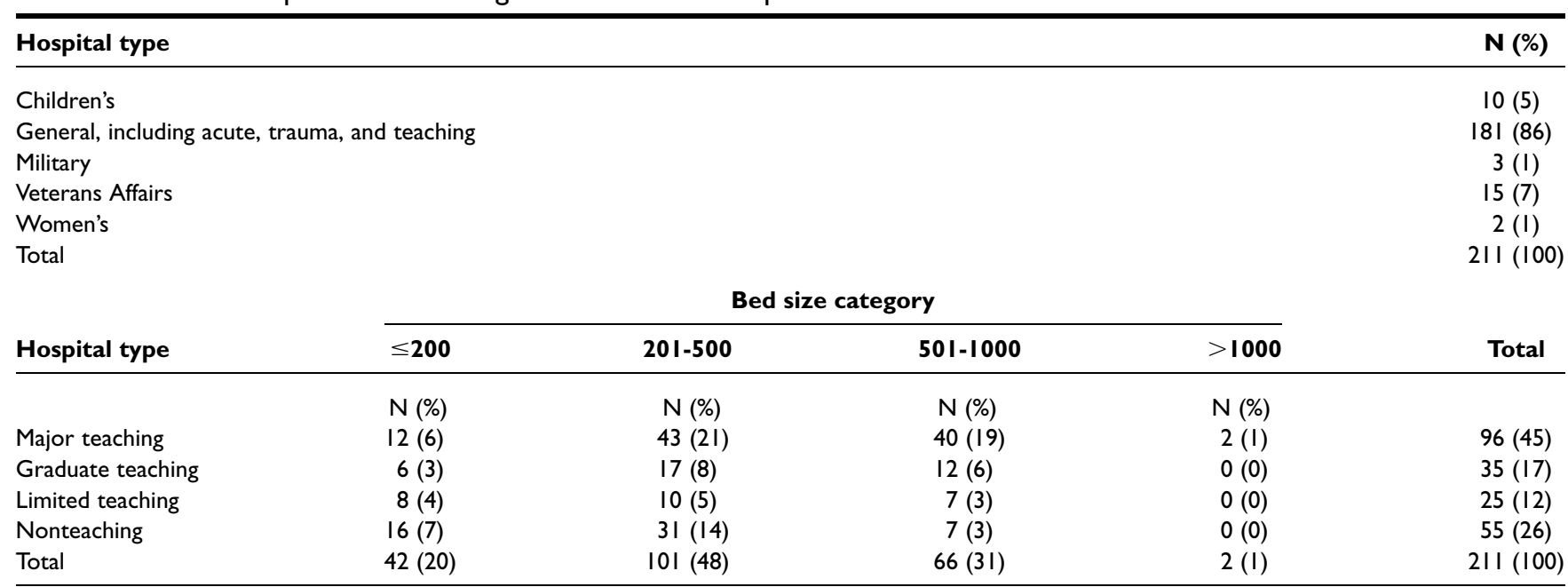

Major: Hospital is an important part of the teaching program of the medical school, and the majority of medical students rotates through multiple clinical services. Graduate: Hospital is used by the medical school for graduate training programs only, ie, residency and/or fellowships.

Limited: Hospital is used in the medical school's teaching program only to a limited extent.

ventilator-associated pneumonias, or urinary catheterassociated urinary tract infections (UTIs) that occur in patients staying in a patient care location such as an intensive care unit (ICU), specialty care area, or ward. In the NHSN, these locations are further characterized according to patient population: adults or children (in Tables, pediatric locations are so noted). In neonatal intensive care unit (NICU) locations (level III or level II/III), ICPs collect data on central line-associated and umbilical catheter-associated primary bloodstream infections or ventilator-associated pneumonia for each of 5 birth-weight categories $(\leq 750 \mathrm{~g}$, 751$1000 \mathrm{~g}, 1001-1500 \mathrm{~g}, 1501-2500 \mathrm{~g}$, and $>2500 \mathrm{~g}$ ). Corresponding location-specific denominator data consisting of patient-days and specific device-days are also collected by ICPs or other trained personnel.

\section{RESULTS}

Characteristics of the 211 NHSN hospitals from 40 states and the District of Columbia that contributed data for this report are shown in Table 1. For the Device-associated module in which data volume was sufficient for this first report, we tabulated deviceassociated infection rates and device utilization (DU) ratios for January through December 2006 (Tables 2-10).

Tables 2 to 4 update and augment previously published device-associated rates and DU ratios by type of non-NICU locations. ${ }^{1,2}$ For inclusion in these Tables, the pooled mean infection rates and DU ratios required data from at least 10 different locations of a given type. For the percentile distributions, data from at least 20 different locations are required. Each of the analyses of Device-associated module data excluded rates or
DU ratios for locations that did not report at least 50 device-days or patient-days. Because of this, the number of locations contributing data varies in the Tables.

Three new locations-pediatric medical/surgical ICU, medical ward, and medical/surgical ward-had sufficient data to be included in this report. The number of locations that were neurosurgical ICU or medical ward was not adequate to provide distributions of any infection rates and DU ratios. For burn ICU, there were insufficient data for ventilator-associated pneumonia and catheter-associated UTI rate and corresponding DU ratio distributions. For trauma ICU, insufficient data were available for ventilator-associated pneumonia rate distributions and for catheterassociated UTI rate and urinary catheter utilization ratio distributions.

The data for adult combined medical/surgical ICUs were split into 2 groups by type of hospital: "major teaching" and "all others." Major teaching status was defined as a hospital that is an important part of the teaching program of a medical school and the majority of medical students rotates through multiple clinical services (see also footnote to Table 1).

For the Device-associated module, in non-NICU locations, the device-days consisted of the total number of central line-days, urinary catheter-days, and ventilatordays. The DU of a location is one measure of invasive practices in that location and constitutes an extrinsic risk factor for HAI. ${ }^{2}$ DU may also serve as a marker for severity of illness of patients, that is, patients' intrinsic susceptibility to infection.

Tables 5 to 10 update and augment the previously published, device-associated rates and DU ratios from 
Table 2. Pooled means and key percentiles of the distribution of central line-associated BSI rates and central line utilization ratios, by type of location, DA module, 2006

Percentile

Central line-associated BSI rate* No. of locations No. of CLAB Central line-days Pooled mean $\quad$ 10\% $\quad 25 \% \quad 50 \%$ (median) $\quad 75 \% \quad 90 \%$

\section{Type of location}

Burn ICU

Coronary ICU

Surgical cardiothoracic ICU

Medical ICU

Medical/surgical ICU

Major teaching

All others

Pediatric medical/surgical ICU

Neurosurgical ICU

Surgical ICU

Trauma ICU

Inpatient medical ward

Inpatient medical/surgical ward

$\begin{array}{rrr}14 & 127 & 18,612 \\ 53 & 181 & 63,941 \\ 51 & 150 & 92,484 \\ 73 & 489 & 170,719 \\ & & \\ 63 & 304 & 128,502 \\ 102 & 431 & 198,551 \\ 36 & 255 & 48,144 \\ 19 & 75 & 21,412 \\ 72 & 378 & 137,484 \\ 21 & 182 & 39,635 \\ 18 & 51 & 24,218 \\ 26 & 58 & 38,340\end{array}$

6.8

$\begin{array}{llllll}2.8 & 0.0 & 0.0 & 2.0 & 4.2 & 6.5\end{array}$

$\begin{array}{llllll}1.6 & 0.0 & 0.0 & 1.2 & 2.8 & 4.1\end{array}$

$\begin{array}{llllll}2.9 & 0.0 & 0.8 & 2.2 & 4.2 & 6.2\end{array}$

$\begin{array}{llllll}2.4 & 0.0 & 0.6 & 1.9 & 3.1 & 5.5\end{array}$

$\begin{array}{llllll}2.2 & 0.0 & 0.0 & 1.0 & 2.3 & 4.5\end{array}$

$\begin{array}{llllll}5.3 & 0.0 & 1.1 & 3.5 & 6.5 & 9.4\end{array}$

3.5

2.7

4.6

$\begin{array}{ll}0.0 & 0.9\end{array}$

2.0

$\begin{array}{ll}4.4 & 7.4\end{array}$

$\begin{array}{lllll}0.0 & 0.4 & 3.3 & 6.5 & 8.5\end{array}$

$\begin{array}{lllll}0.0 & 0.0 & 0.0 & 1.8 & 3.6\end{array}$

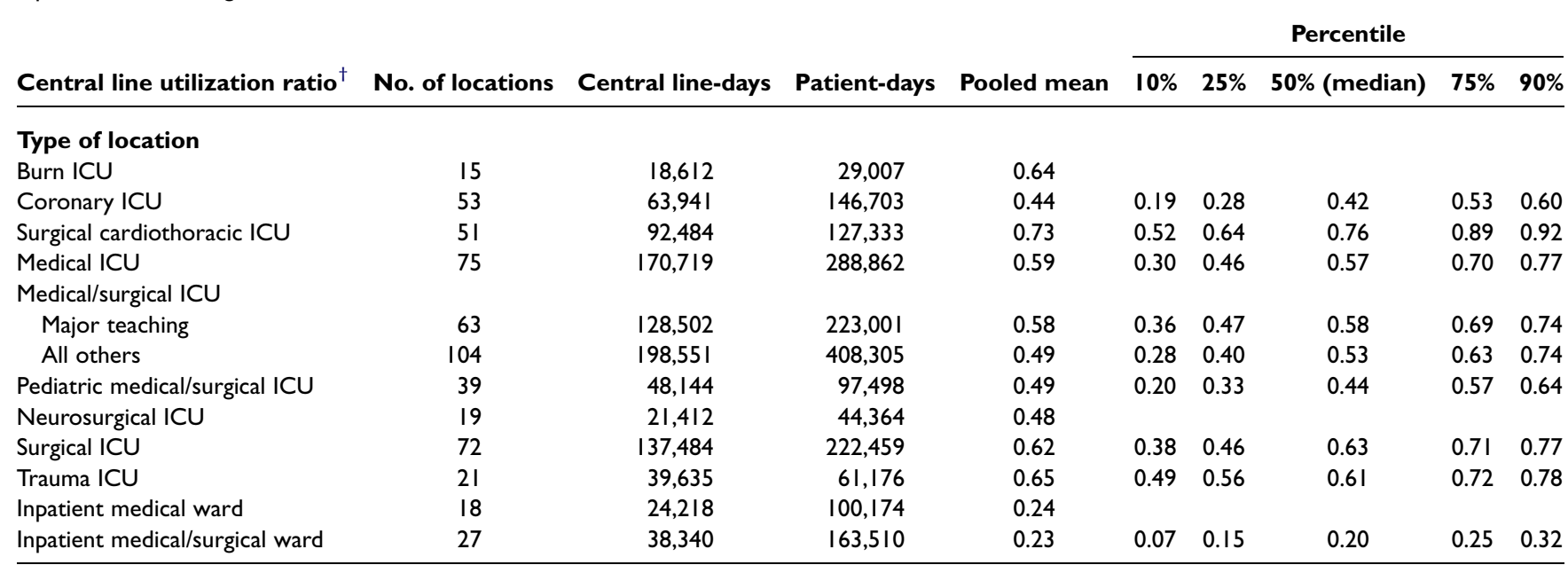

$B S I$, bloodstream infection; CLAB, central line-associated BSI.

$* \frac{\text { Number of CLAB }}{\text { Number of central line-days }} \times 1000$.

$\dagger$ Number of central line-days

$\frac{\text { Number of central line-days }}{\text { Number of patient-days }}$.

the High Risk Nursery Component of the NNIS system. ${ }^{1,3}$ New for the NHSN Report are the 2 lowest birth-weight categories and separate Tables for central line-associated bloodstream infections (BSI), umbilical catheter-associated BSI, and ventilator-associated pneumonia in level III and level II/III NICUs. For NICUs in the Device-associated module, device-days consist of the total number of central line-days, umbilical catheterdays, and ventilator-days. Each of the analyses of NICU data excluded rates or DU ratios for units that did not report at least 50 device-days or patient-days. Because of this, the number of units contributing data varies in the Tables. Although the percentile distribution of the rates is provided, for most birth-weight categories the number of ventilator-associated pneumonias and ventilator-days is still small and the data should be considered provisional.
Tables 11 to 17 are new for this report and provide data on select attributes of the device-associated infections for each location. For example, Tables 11, 14, and 15 show the frequency and percentage distribution of the specific sites of BSI and the criterion used for identifying these infections. Note that for adult and pediatric ICUs and wards, only laboratory-confirmed BSI are allowed and shown, whereas clinical sepsis is included as a valid BSI specific site for neonates in NICU. For some of the patient care locations in these Tables, the number of central line-associated BSI does not exactly match those shown in the rates Tables because of an omission in the business logic in an early version of the NHSN Web interface. A total of 33 device-associated laboratoryconfirmed BSIs for adult and pediatric ICU/wards did not have a criterion reported; the same was true for 5 BSIs in level III NICUs and 1 BSI in level II/III NICUs. 
Table 3. Pooled means and key percentiles of the distribution of urinary catheter-associated UTI rates and urinary catheter utilization ratios, by type of location, DA module, 2006

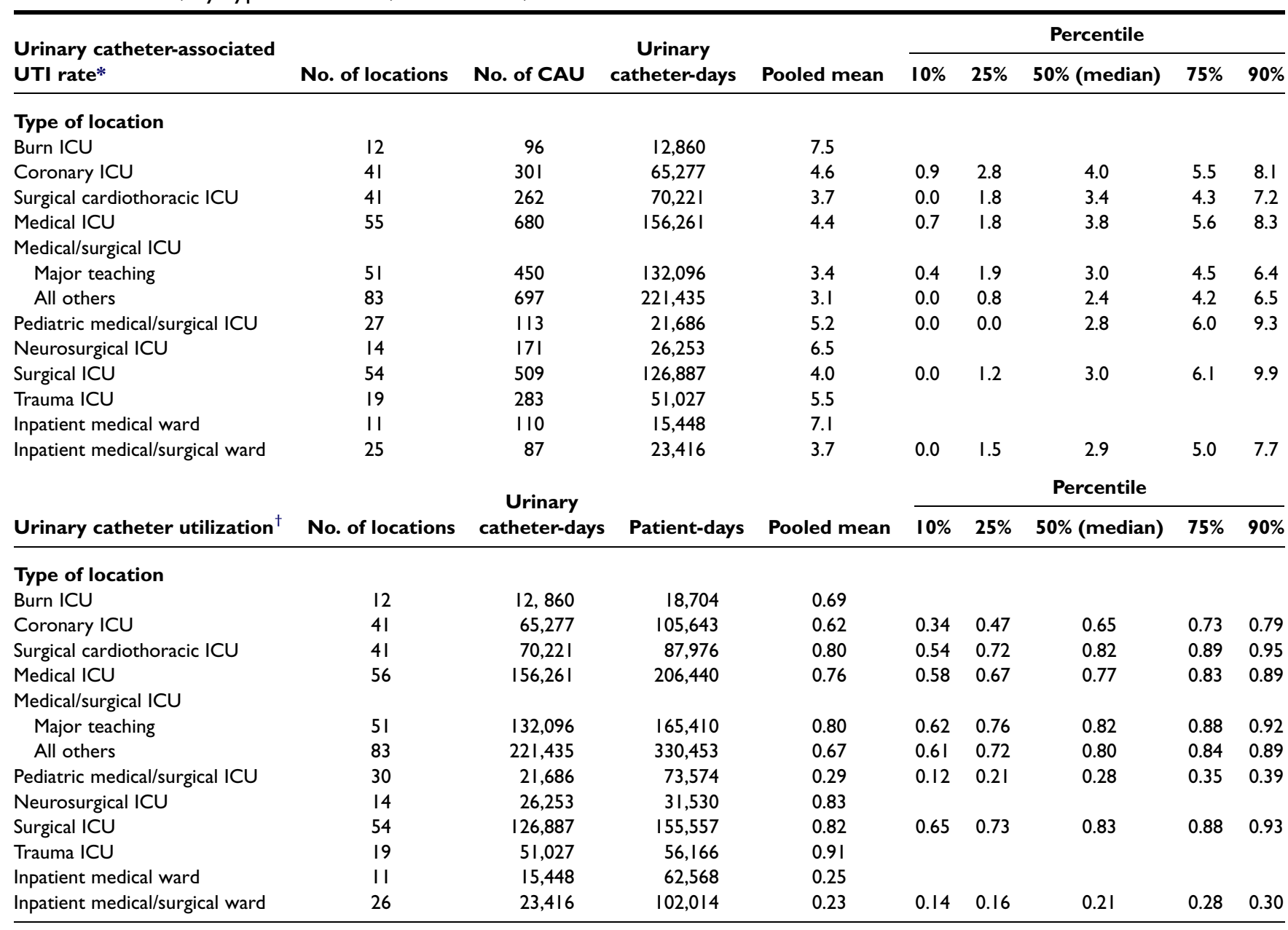

UTI, urinary tract infection; CAU, catheter-associated UTI.

$* \frac{\text { Number of } \mathrm{CAU}}{\text { Number of urinary catheter-days }} \times 1000$.

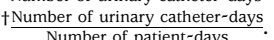

\section{DISCUSSION}

These data are the first reported from the new NHSN. Although NHSN facilities began collecting data on paper in 2005, the Web interface was not available for use until the end of October 2005. Thus, because many facilities were unable to enter data for 2005 , we elected to consider that year as a pilot test of the system and, hence, included only data from January 2006 forward.

The hospitals reporting data included in this report are a subset of those that were members of the NNIS system, and the characteristics shown in Table 1 reflect this. However, as more states elect to use the NHSN as their system for meeting mandatory HAI reporting requirements and as enrollment is opened to all facilities, we expect to have a more diverse group of healthcare facilities reporting in the future.
Comparisons of these data with those of like locations from the last NNIS Report may be misleading. As noted in the results, it is not possible to compare the NICU data with the High Risk Nursery data of the NNIS system because of the multiple changes implemented in NHSN and because the volume of data is still limited for several of the birth-weight categories. Another difference in the NHSN is that data from pediatric ICUs are no longer combined with adult ICU data (eg, in the NNIS, pediatric surgical ICUs were combined with adult surgical ICUs). Data from pediatric ICU types are now reported as their own specialty types; for instance, pediatric medical/surgical ICU is separated and had sufficient data for inclusion in this report. Another example is that, in the NNIS Report, the central lineassociated BSI rate for medical ICU was 5.0, and, in this report, it is 2.9. Two factors may account for this difference: (1) a change in the numerator in 2006 
Table 4. Pooled means and key percentiles of the distribution of ventilator-associated PNEU rates and ventilator utilization ratios, by type of location, DA module, 2006

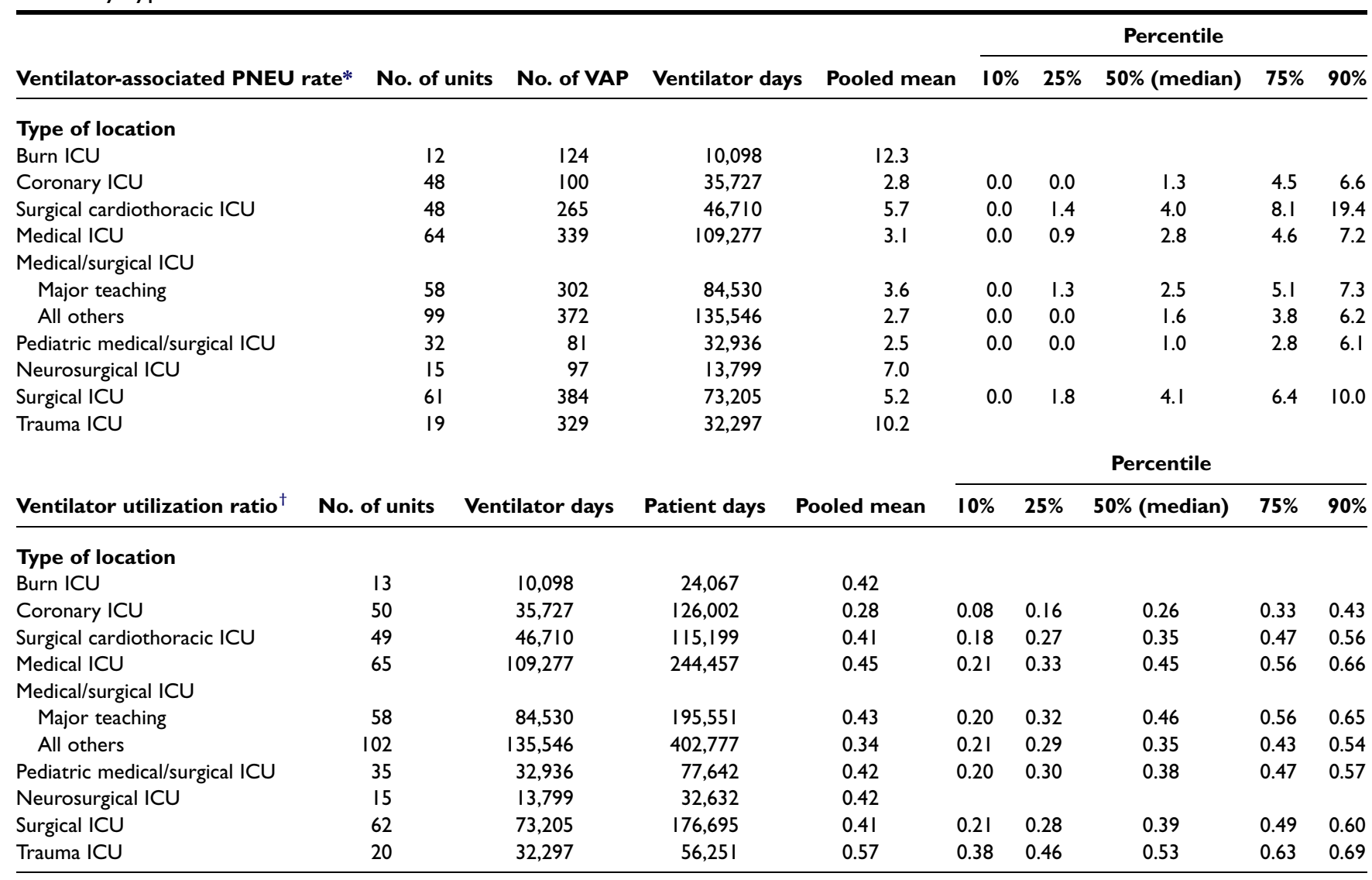

PNEU, pneumonia infection; VAP, ventilator-associated PNEU.

$* \frac{\text { Number of VAP }}{\text { Number of ventilator-days }} \times 1000$.

$+\frac{\text { Number of ventilator-days }}{\text { Number of patient-days }}$.

Table 5. Pooled means and key percentiles of the distribution of central line-associated BSI rates and central line utilization ratios for level III NICUs, DA module, 2006

\begin{tabular}{|c|c|c|c|c|c|c|c|c|c|}
\hline Birth-weight category & No. of units & No. of CLAB & Central line-days & Pooled mean & \multicolumn{5}{|c|}{ Percentile } \\
\hline \multicolumn{10}{|c|}{ Central line-associated BSI rate* } \\
\hline$\leq 750 \mathrm{~g}$ & 42 & 118 & 18,458 & 6.4 & 0.0 & 2.5 & 5.2 & 11.0 & 15.6 \\
\hline $75 \mathrm{I}-1000 \mathrm{~g}$ & 44 & 83 & $|8,78|$ & 4.4 & 0.0 & 0.0 & 3.8 & 8.7 & 10.2 \\
\hline $1001-1500 \mathrm{~g}$ & 42 & 87 & 17,968 & 4.8 & 0.0 & 0.0 & 3.6 & 7.5 & 14.0 \\
\hline $150 \mid-2500 \mathrm{~g}$ & 36 & 68 & 16,208 & 4.2 & 0.0 & 0.0 & 0.0 & 4.1 & 8.5 \\
\hline$>2500 \mathrm{~g}$ & & & & & \multicolumn{5}{|c|}{ Percentile } \\
\hline Birth-weight category & No. of units & Central line-days & Patient-days & Pooled mean & $10 \%$ & $25 \%$ & $50 \%$ (median) & $75 \%$ & $90 \%$ \\
\hline \multicolumn{10}{|c|}{ Central line utilization ratio ${ }^{\dagger}$} \\
\hline$\leq 750 \mathrm{~g}$ & 45 & 18,458 & 57,896 & 0.32 & 0.20 & 0.27 & 0.32 & 0.43 & 0.52 \\
\hline $75 \mathrm{I}-1000 \mathrm{~g}$ & 47 & $|8,78|$ & 61,132 & 0.31 & 0.17 & 0.21 & 0.34 & 0.44 & 0.53 \\
\hline
\end{tabular}

BSI, bloodstream infection; CLAB, central line-associated BSI.

$* \frac{\text { Number of CLAB }}{\text { Number of central line-days }} \times 1000$.

† Number of central line-days

Number of patient-days . 
Table 6. Pooled means and key percentiles of the distribution of umbilical catheter-associated BSI rates and umbilical catheter utilization ratios for level III NICUs, DA module, 2006

\begin{tabular}{|c|c|c|c|c|c|c|c|c|c|c|c|c|c|}
\hline \multicolumn{2}{|c|}{$\begin{array}{l}\text { Umbilical catheter-associated } \\
\text { BSI rate* }\end{array}$} & No. of units & \multicolumn{2}{|c|}{ No. of UCAB } & \multicolumn{2}{|c|}{$\begin{array}{l}\text { Umbilical } \\
\text { catheter-days }\end{array}$} & \multicolumn{2}{|c|}{ Pooled mean } & \multicolumn{5}{|c|}{ Percentile } \\
\hline$\leq 750 \mathrm{~g}$ & & 36 & 4 & & 611 & & 6.9 & & 0.00 & 0.00 & 2.90 & 10.80 & 19.10 \\
\hline $75 \mathrm{I}-1000 \mathrm{~g}$ & & 34 & 2 & & 560 & & 4.3 & & 0.00 & 0.00 & 0.00 & 0.00 & 9.50 \\
\hline $1001-1500 \mathrm{~g}$ & & 32 & 2 & & 630 & & 3.2 & & 0.00 & 0.00 & 0.00 & 0.00 & 14.50 \\
\hline \multirow{2}{*}{$\begin{array}{l}\text { Umbilical catheter } \\
\text { utilization ratio }\end{array}$} & \multirow{2}{*}{\multicolumn{3}{|c|}{$\begin{array}{l}\text { Umbilical } \\
\text { catheter-days }\end{array}$}} & \multirow{2}{*}{\multicolumn{2}{|c|}{ Patient-days }} & \multirow{2}{*}{\multicolumn{2}{|c|}{ Pooled mean }} & \multicolumn{6}{|c|}{ Percentile } \\
\hline & & & & & & & & $10 \%$ & & $5 \%$ & $50 \%$ (median) & $75 \%$ & $90 \%$ \\
\hline \multicolumn{14}{|l|}{ Birth-weight category } \\
\hline$\leq 750 \mathrm{~g}$ & 44 & \multicolumn{2}{|c|}{6116} & \multicolumn{2}{|c|}{53,523} & & 0.11 & 0.05 & \multicolumn{2}{|c|}{0.07} & 0.12 & 0.24 & 0.30 \\
\hline
\end{tabular}

$B S I$, bloodstream infection; UCAB, umbilical catheter-associated BSI.

$* \frac{\text { Number of UCAB }}{\text { Number of umbilical catheter-days }} \times 1000$.

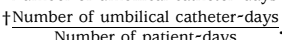

Table 7. Pooled means and key percentiles of the distribution of central line-associated BSI rates and central line utilization ratios for level II/III NICUs, DA module, 2006

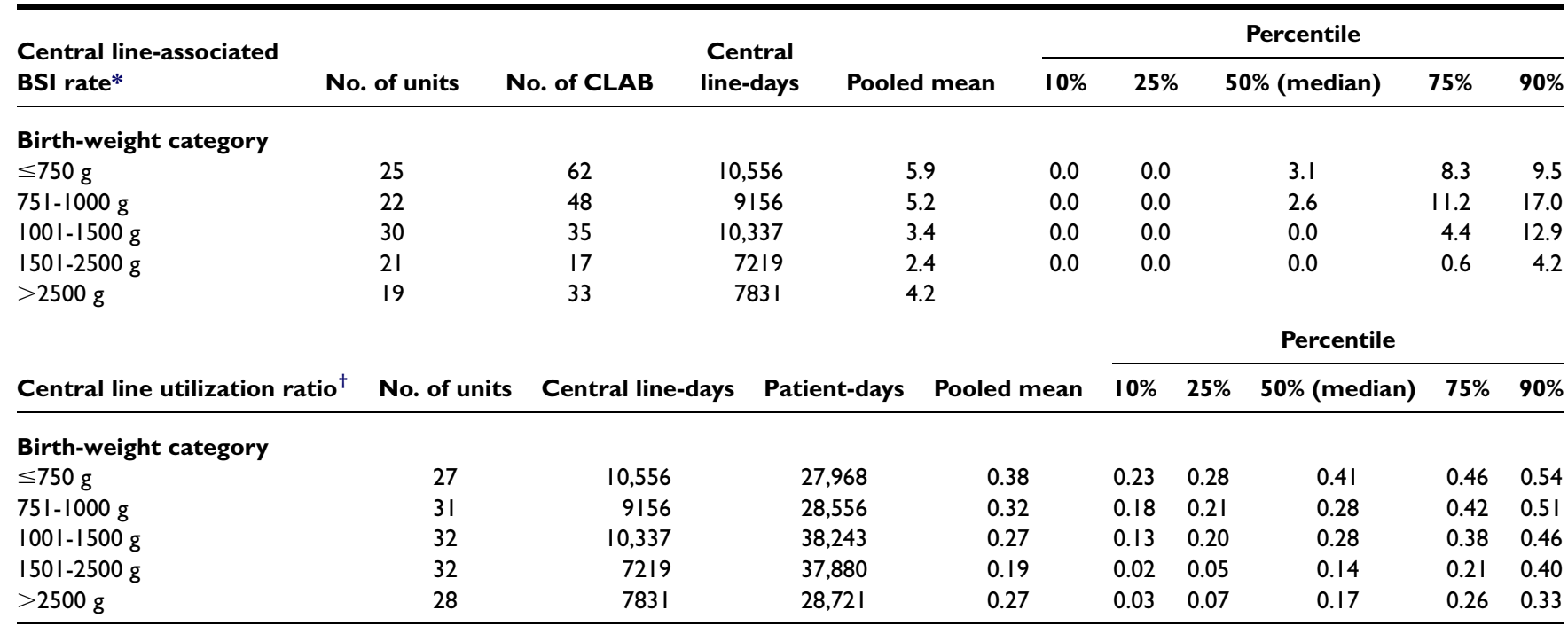

$B S I$, bloodstream infection; CLAB, central line-associated BSI.

$* \frac{\text { Number of CLAB }}{\text { Number of central line-days }} \times 1000$.

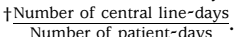

such that only central line-associated laboratoryconfirmed BSIs were included, whereas, previously, clinical sepsis infections were also included, and (2) an actual reduction in the number of BSI. This latter factor may be particularly likely because BSI prevention campaigns have been implemented by many hospitals since 2001 . $^{6-8}$

Tables 11 to 17 were included to aid the reader in interpreting the rates data. For example, most of the central line-associated and umbilical catheter-associated 
Table 8. Pooled means and key percentiles of the distribution of umbilical catheter-associated BSI rates and umbilical catheter utilization ratios for level II/III NICUs, DA module, 2006

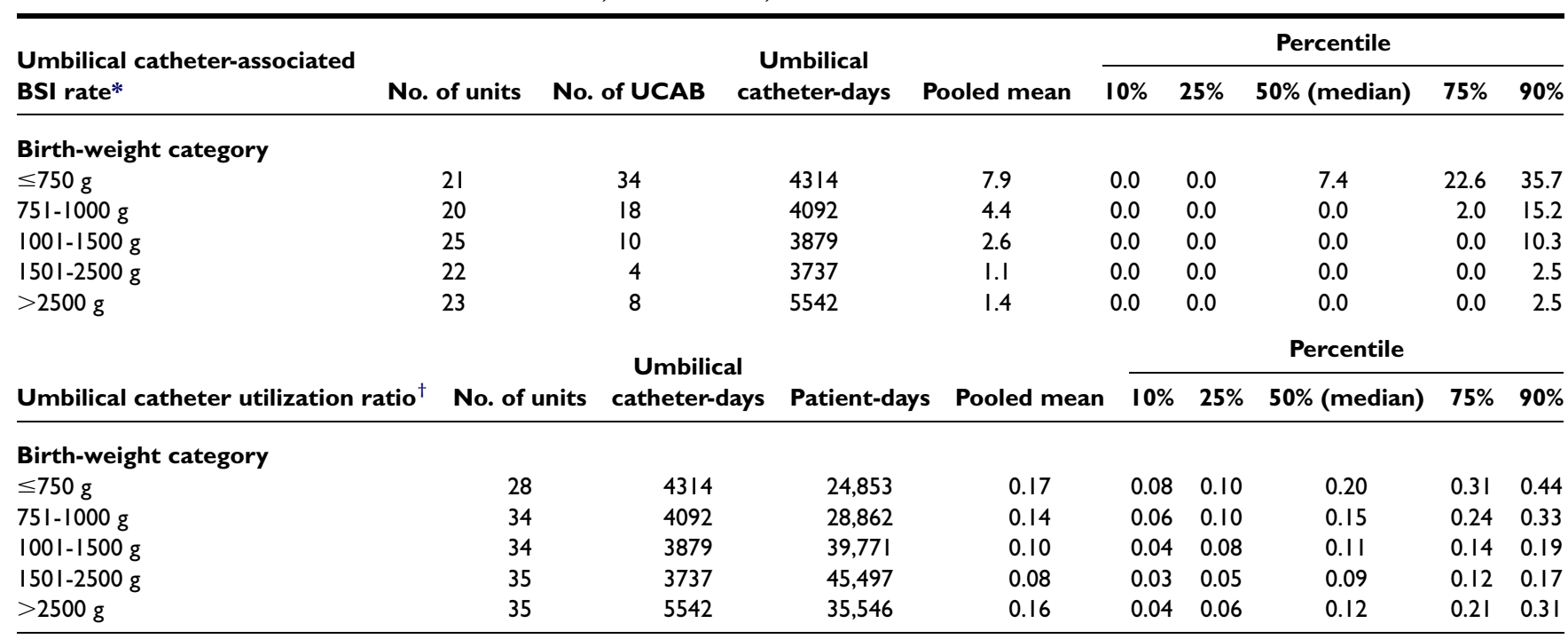

$B S I$, bloodstream infection; UCAB, umbilical catheter-associated BSI.

$* \frac{\text { Number of UCAB }}{\text { Number of umbilical catheter-days }} \times 1000$.

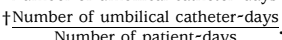

Table 9. Pooled means and key percentiles of the distribution of ventilator-associated PNEU rates and ventilator utilization ratios for level III NICUs, DA module, 2006

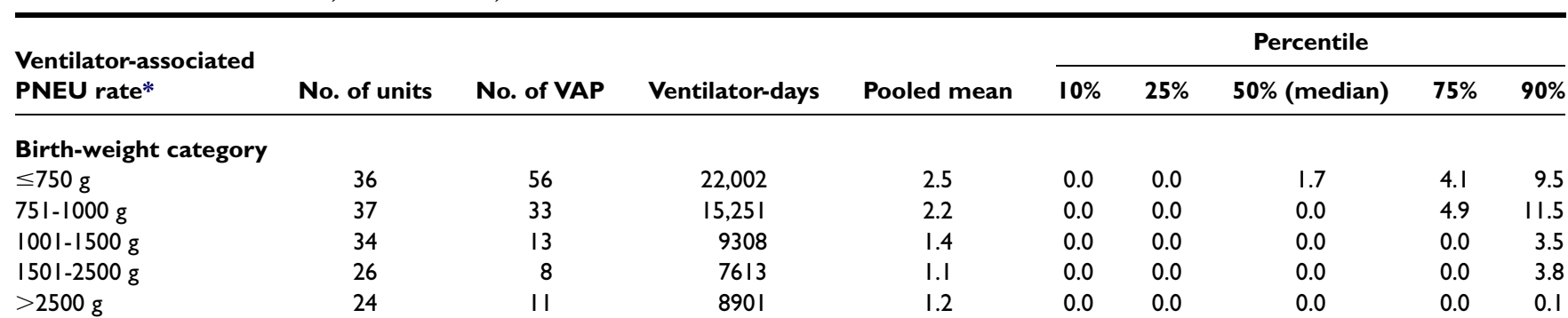

\begin{tabular}{|c|c|c|c|c|c|c|c|c|c|}
\hline Ventilator utilization ratio $^{\dagger}$ & No. of units & Ventilator-days & Patient-days & Pooled mean & \multicolumn{5}{|c|}{ Percentile } \\
\hline \multicolumn{10}{|l|}{ Birth-weight category } \\
\hline$\leq 750 \mathrm{~g}$ & 37 & 22,002 & $4 I, 354$ & 0.53 & 0.32 & 0.43 & 0.51 & 0.68 & 0.80 \\
\hline $751-1000 \mathrm{~g}$ & 39 & $|5,25|$ & 45,089 & 0.34 & 0.14 & 0.19 & 0.29 & 0.48 & 0.62 \\
\hline $1001-1500 \mathrm{~g}$ & 39 & 9308 & 60,905 & 0.15 & 0.06 & 0.10 & 0.14 & 0.28 & 0.40 \\
\hline $150 \mid-2500 \mathrm{~g}$ & 39 & 7613 & 78,083 & 0.10 & 0.02 & 0.04 & 0.06 & 0.17 & 0.31 \\
\hline
\end{tabular}

PNEU, pneumonia infection; VAP, ventilator-associated PNEU.

$* \frac{\text { Number of VAP }}{\text { Number of ventilator-days }} \times 1000$.

$\frac{\dagger \text { Number of ventilator-days }}{\text { Number of patient-days }}$.

BSI were identified using the most objective criterion $(1 \mathrm{a})^{5}$; however, for adult and pediatric locations, there was considerable variation. Similarly, the specific site of ventilator-associated pneumonia most frequently reported used the clinical criteria of PNU1 for all locations. ${ }^{5}$ However, in adult and pediatric locations, nearly $40 \%$ of ventilator-associated pneumonias reported used the more rigorous criteria of PNU2 and PNU3. ${ }^{5}$ The specific site of catheter-associated UTI most frequently reported was symptomatic UTI. However, the distinction between this type of UTI and asymptomatic bacteriuria is often only the presence 
Table 10. Pooled means and key percentiles of the distribution of ventilator-associated PNEU rates and ventilator utilization ratios for level II/III NICUs, DA module, 2006

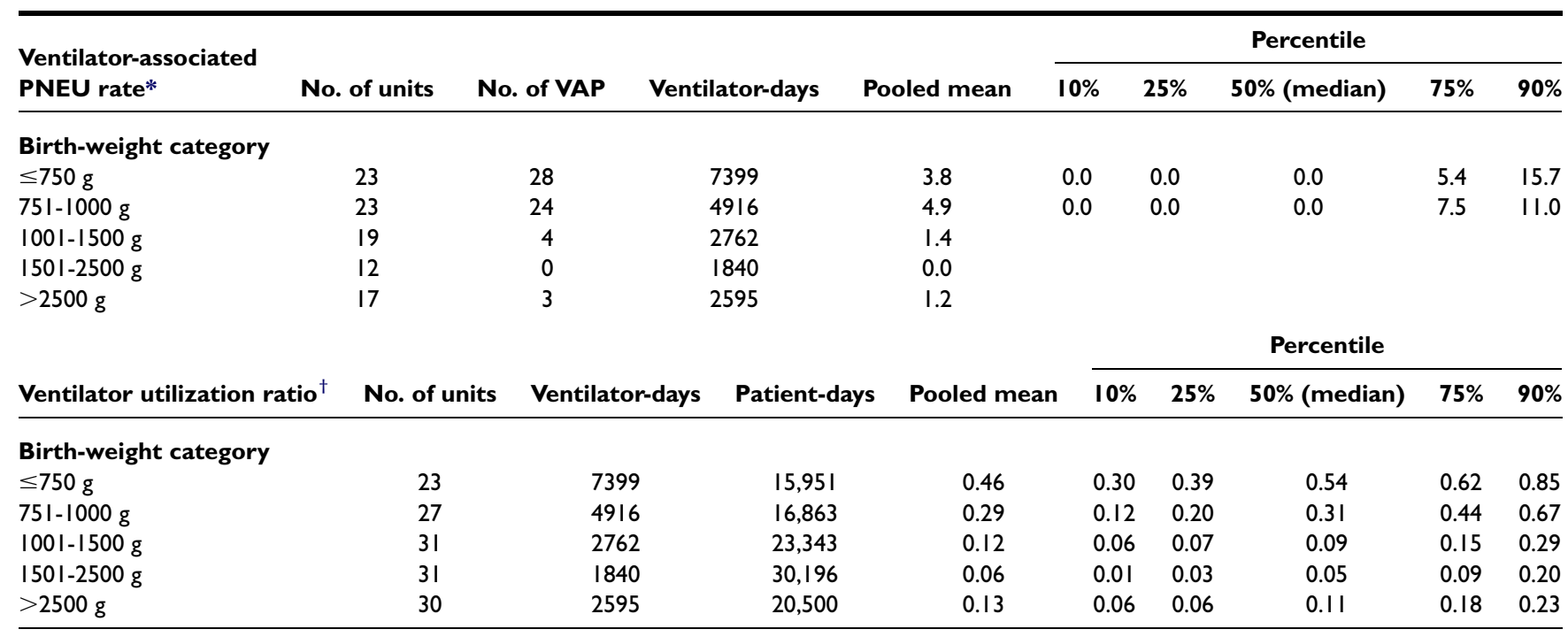

PNEU, pneumonia infection; VAP, ventilator-associated PNEU.

$* \frac{\text { Number of VAP }}{\text { Number of ventilator-days }} \times 1000$.

+ Number of ventilator-days

Number of patient-days

Table II. Distribution of criteria for central line-associated laboratory confirmed BSI by location, 2006

\begin{tabular}{|c|c|c|c|c|c|c|c|}
\hline Type of location & \multicolumn{2}{|c|}{ Criterion I } & \multicolumn{2}{|c|}{ Criterion $2 \mathrm{a}$} & \multicolumn{2}{|c|}{ Criterion $\mathbf{2 b}$} & Total \\
\hline Coronary ICU & 120 & 67.0 & 36 & 20.1 & 23 & 12.8 & 179 \\
\hline Surgical cardiothoracic ICU & 96 & 66.7 & 29 & 20.1 & 19 & 13.2 & 144 \\
\hline Medical ICU & 332 & 69.0 & 76 & 15.8 & 73 & 15.2 & 481 \\
\hline \multicolumn{8}{|l|}{ Medical/surgical ICU } \\
\hline Pedatric medical/surgical ICU & 133 & 52.2 & 34 & 13.3 & 88 & 34.5 & 255 \\
\hline Neurosurgical ICU & 39 & 52.7 & 13 & 17.6 & 22 & 29.7 & 74 \\
\hline Surgical ICU & 266 & 71.3 & 48 & 12.9 & 59 & 15.8 & 373 \\
\hline Trauma ICU & 154 & 86.0 & 13 & 7.3 & 12 & 6.7 & 179 \\
\hline Inpatient medical ward & 41 & 80.4 & 7 & 13.7 & 3 & 5.9 & $5 \mathbf{I}$ \\
\hline Inpatient medical/surgical & 35 & 60.3 & 18 & 31.0 & 5 & 8.6 & 58 \\
\hline
\end{tabular}

See Centers for Disease Control and Prevention ${ }^{5}$ for criteria.

$B S I$, bloodstream infection.

of fever, ${ }^{5}$ which can be difficult to attribute completely to infection versus other processes in critically ill patients.

If you would like to compare your hospital's rates and ratios with those in this report, you must first collect information from your hospital in accordance with the methods described for the NHSN System. ${ }^{4,5}$ You should also refer to Appendices A and B for further instructions. Appendix A discusses the calculation of infection rates and DU ratios for the Device-associated module. Appendix B gives a step-by-step method for interpretation of percentiles of infection rates or DU ratios. A high rate or ratio ( $>90$ th percentile) does not necessarily define a problem; it only suggests an area for further investigation. Similarly, a low rate or ratio $(<10$ th percentile) may be the result of inadequate infection detection. Hospitals should use these data to guide local prevention strategies and other quality improvement efforts aimed at reducing infection rates as much as possible. 
Table I2. Distribution of specific sites of ventilator-associated pneumonia by location, 2006

\begin{tabular}{|c|c|c|c|c|c|c|c|}
\hline Type of location & \multicolumn{2}{|c|}{ PNUI } & \multicolumn{2}{|c|}{ PNU2 } & \multicolumn{2}{|c|}{ PNU3 } & Total \\
\hline Burn ICU & 90 & 72.6 & 33 & 26.6 & I & 0.8 & 124 \\
\hline Coronary ICU & 55 & 55.0 & 43 & 43.0 & 2 & 2.0 & 100 \\
\hline Surgical cardiothoracic ICU & 144 & 54.3 & 119 & 44.9 & 2 & 0.8 & 265 \\
\hline Medical ICU & 274 & 80.8 & 61 & 18.0 & 4 & 1.2 & 339 \\
\hline \multicolumn{8}{|l|}{ Medical/surgical ICU } \\
\hline Pedatric medical/surgical ICU & 67 & 82.7 & 13 & 16.1 & I & 1.2 & 81 \\
\hline Neurosurgical ICU & 45 & 46.4 & 52 & 53.6 & 0 & 0.0 & 97 \\
\hline Surgical ICU & 261 & 68.0 & 111 & 28.9 & 12 & 3.1 & 384 \\
\hline Trauma ICU & 142 & 43.2 & 186 & 56.5 & I & 0.3 & 329 \\
\hline Total & 1449 & 60.7 & 920 & 38.3 & 24 & 1.0 & 2393 \\
\hline
\end{tabular}

See Centers for Disease Control and Prevention ${ }^{5}$ for specific sites.

Table 13. Distribution of specific sites of urinary catheter-associated UTI by location, 2006

\begin{tabular}{|c|c|c|c|c|c|}
\hline Type of location & \multicolumn{2}{|c|}{ ASB } & \multicolumn{2}{|c|}{ SUTI } & Total \\
\hline Burn ICU & 24 & 25.0 & 72 & 75.0 & 96 \\
\hline Coronary ICU & $14 \mid$ & 46.8 & 160 & 53.2 & 301 \\
\hline Surgical cardiothoracic ICU & 118 & 45.0 & 144 & 55.0 & 262 \\
\hline Medical ICU & 254 & 37.4 & 426 & 62.7 & 680 \\
\hline \multicolumn{6}{|l|}{ Medical/surgical ICU } \\
\hline Pedatric medical/surgical ICU & 24 & 21.2 & 89 & 78.8 & 113 \\
\hline Neurosurgical ICU & 59 & 34.5 & 112 & 65.5 & |7| \\
\hline Surgical ICU & 228 & 44.8 & 281 & 55.2 & 509 \\
\hline Trauma ICU & 61 & 21.6 & 222 & 78.5 & 283 \\
\hline Inpatient medical ward & 52 & 47.3 & 58 & 52.7 & 110 \\
\hline Inpatient medical/surgical & 50 & 57.5 & 37 & 42.5 & 87 \\
\hline
\end{tabular}

See Centers for Disease Control and Prevention ${ }^{5}$ for specific sites.

ASB, asymptomatic bacteriuria; SUTI, symptomatic urinary tract infection; UTI, urinary tract infection.

Table I4. Distribution of specific sites and criteria for device-associated BSI among level III NICUs by birth weight, 2006

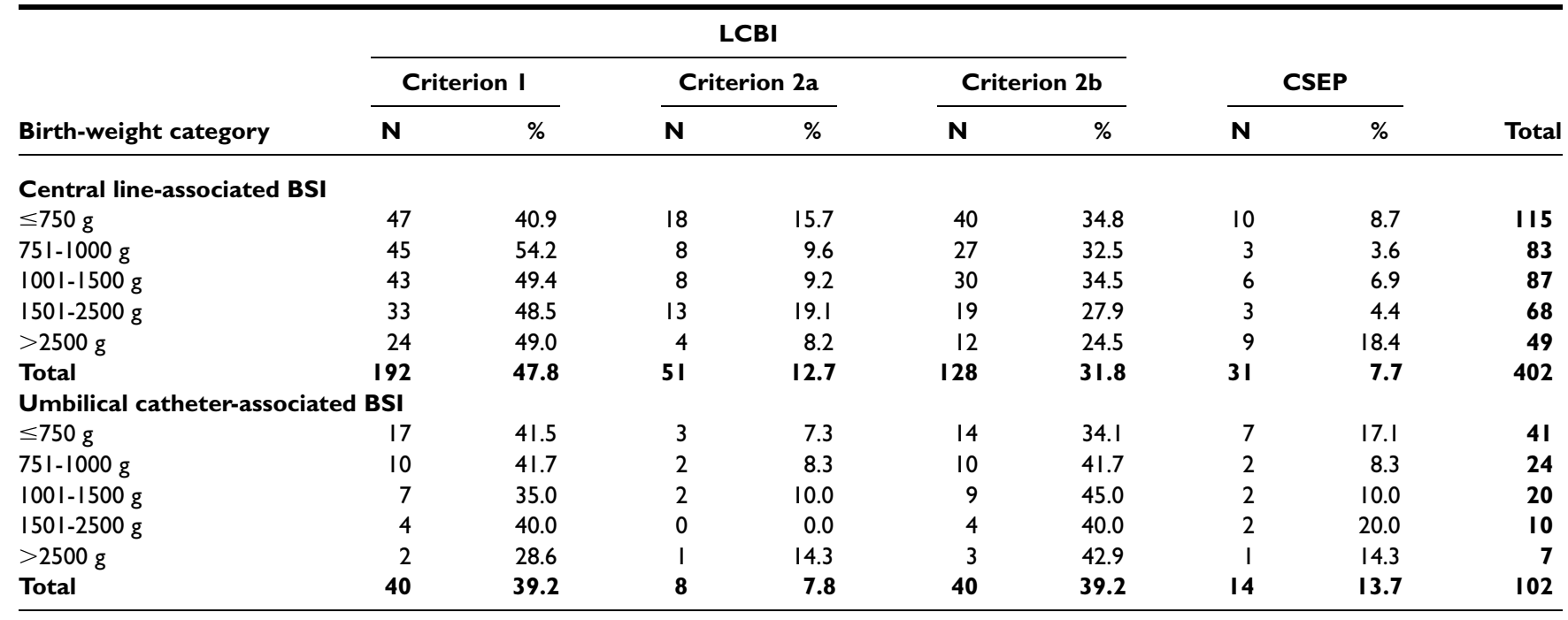

See Centers for Disease Control and Prevention ${ }^{5}$ for specific sites.

$B S I$, bloodstream infection; CSEP, clinical sepsis. 
Table I5. Distribution of specific sites and criteria for device-associated BSI among level II/III NICUs by birth weight, 2006

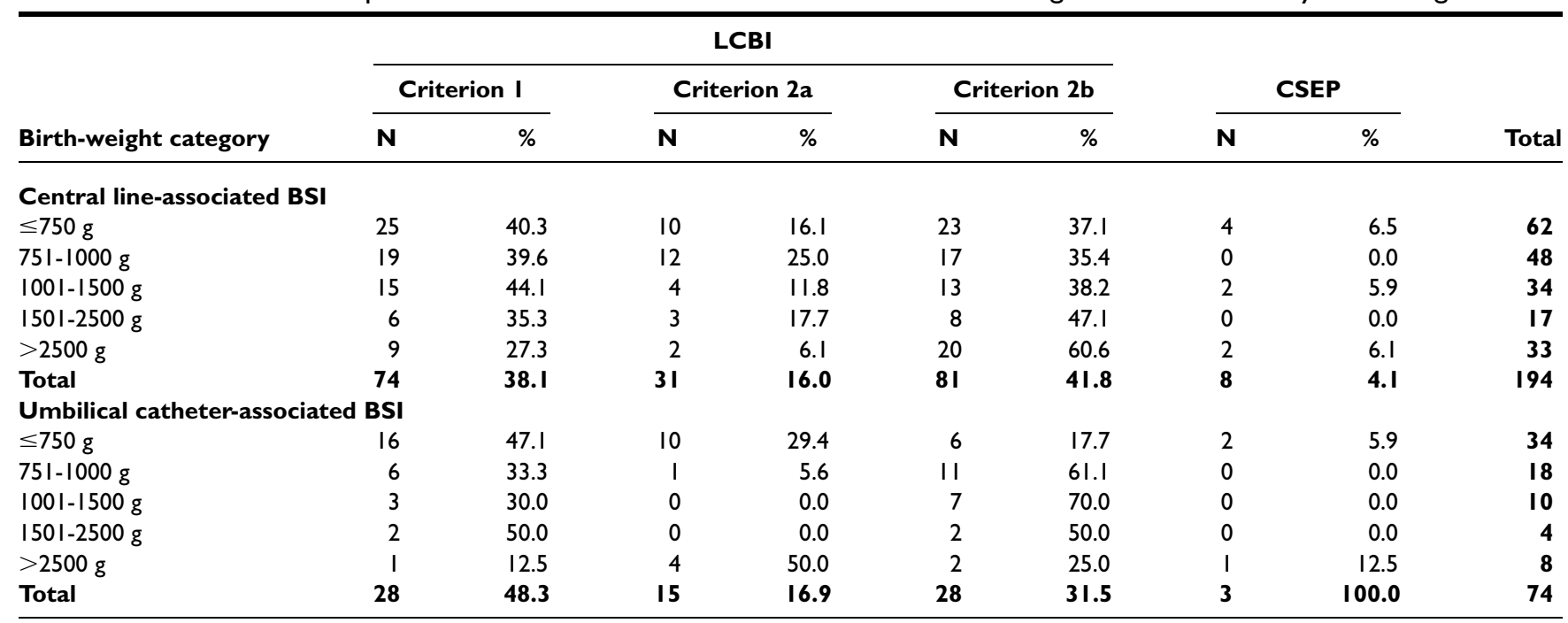

See Centers for Disease Control and Prevention ${ }^{5}$ for specific sites and criteria.

$B S I$, bloodstream infection; CSEP, clinical sepsis.

Table 16. Distribution of specific sites of ventilator-associated pneumonia among level III NICUs by birth weight, 2006

\begin{tabular}{|c|c|c|c|c|c|c|c|}
\hline \multirow[b]{2}{*}{ Birth-weight category } & \multicolumn{2}{|c|}{ PNUI } & \multicolumn{2}{|c|}{ PNU2 } & \multicolumn{2}{|c|}{ PNU3 } & \multirow[b]{2}{*}{ Total } \\
\hline & $\mathbf{N}$ & $\%$ & $\mathbf{N}$ & $\%$ & $\mathbf{N}$ & $\%$ & \\
\hline$\leq 750 \mathrm{~g}$ & 46 & 82.1 & 10 & 17.9 & 0 & 0.0 & 56 \\
\hline $1001-1500 \mathrm{~g}$ & 13 & 100.0 & 0 & 0.0 & 0 & 0.0 & 13 \\
\hline $150 \mid-2500 \mathrm{~g}$ & 7 & 87.5 & I & 12.5 & 0 & 0.0 & 8 \\
\hline$>2500 \mathrm{~g}$ & 9 & 81.8 & 2 & 18.2 & 0 & 0.0 & II \\
\hline
\end{tabular}

See Centers for Disease Control and Prevention ${ }^{5}$ for specific sites.

Table I7. Distribution of specific sites of ventilator-associated pneumonia among level II/III NICUs by birth weight, 2006

\begin{tabular}{|c|c|c|c|c|c|c|c|}
\hline Birth-weight category & \multicolumn{2}{|c|}{ PNUI } & \multicolumn{2}{|c|}{ PNU2 } & \multicolumn{2}{|c|}{ PNU3 } & Tota \\
\hline$\leq 750 \mathrm{~g}$ & 17 & 60.7 & 11 & 39.3 & 0 & 0.0 & 28 \\
\hline $750-1000 \mathrm{~g}$ & 20 & 83.3 & 4 & 16.7 & 0 & 0.0 & 24 \\
\hline $1001-1500 \mathrm{~g}$ & I & 25.0 & 3 & 75.0 & 0 & 0.0 & 4 \\
\hline $150 \mid-2500 \mathrm{~g}$ & 0 & 0.0 & 0 & 0.0 & 0 & 0.0 & 0 \\
\hline$>2500 \mathrm{~g}$ & 2 & 66.7 & 1 & 33.3 & 0 & 0.0 & 3 \\
\hline
\end{tabular}

See Centers for Disease Control and Prevention ${ }^{5}$ for specific sites.

The authors thank the NHSN participants for their ongoing efforts to monitor infections and improve patient safety and our colleagues in the Division of Healthcare Quality Promotion, who tirelessly support this unique public health network.

\section{References}

I. CDC NNIS System. National Nosocomial Infections Surveillance (NNIS) system report, data summary from January 1992 to June 2004, issued October 2004. Am J Infect Control 2004;32:440-85.

2. Jarvis WR, Edwards JR, Culver DH, Hughes JM, Horan T, Emori TG, et al. Nosocomial infection rates in adult and pediatric intensive care units in the United States. Am J Med I991;91(Suppl 3B):SI85-91.
3. Gaynes RP, Martone WJ, Culver DH, Emori TG, Horan TC, Banerjee $\mathrm{SN}$, et al. Comparison of rates of nosocomial infections in neonatal intensive care units in the United States. Am J Med 1991;91(Suppl 3B): SI92-6.

4. Centers for Disease Control and Prevention. Outline for health care-associated infection surveillance. Available at: http://www. cdc.gov/ncidod/dhqp/nhsn_documents.html (http://www.cdc.gov/ncidod/ dhqp/pdf/nhsn/OutlineForHAISurveillance.pdf). Accessed February 20, 2007.

5. Centers for Disease Control and Prevention. NHSN manual: patient safety component protocols. Available at: http://www.cdc.gov/ncidod/ dhqp/nhsn_documents.html (http://www.cdc.gov/ncidod/dhqp/pdf/nhsn/ 
NHSN_Manual_\%20Patient_Safety_Protocol022307.pdf). Accessed May 7, 2007.

6. Provonost P, Needham D, Berenholtz S, Sinopoli D, Haitao C, Cosgrove $\mathrm{S}$, et al. An intervention to decrease catheter-related bloodstream infections in the ICU. N Engl J Med 2006;355:2725-32.

7. Centers for Disease Control and Prevention. Reduction in central lineassociated bloodstream infection among patients in intensive care units-Pennsylvania, April 200I-March 2005. MMWR Morb Wkly Rep 2005;54:1013-6.

8. Institute for Healthcare Improvement. Saving 100,000 lives campaign. Available at: http://www.ihi.org. Accessed May 7, 2007.

Appendix A. How to calculate a deviceassociated infection rate and device utilization ratio with Device-associated module data

\section{Calculation of device-associated infection rate}

Step 1. Decide on the time period for your analysis. It may be a month, a quarter, 6 months, a year, or some other period.

Step 2. Select the patient population for analysis, ie, the type of location or a birth-weight category in a NICU.

Step 3. Select the infections to be used in the numerator. They must be site specific and must have occurred in the selected patient population. Their date of onset must be during the selected time period.

Step 4. Determine the number of device-days, which is used as the denominator of the rate. Device-days are the total number of days of exposure to the device (central line, umbilical catheter, ventilator, or urinary catheter) by all of the patients in the selected population during the selected time period.

Example: Five patients on the first day of the month had 1 or more central lines in place; 5 on day $2 ; 2$ on day 3 ; 5 on day $4 ; 3$ on day $5 ; 4$ on day 6 ; and 4 on day 7 . Adding the number of patients with central lines on days 1 through 7 , we would have $5+5+2+5+3$ $+4+4=28$ central line-days for the first week. If we continued for the entire month, the number of central line-days for the month is simply the sum of the daily counts.

Step 5. Calculate the device-associated infection rate (per 1000 device-days) using the following formula:

Device-associated infection rate

Number of device-associated infections for an infection site Number device-days

\section{Example:}

Central line-associated BSI rate per 1000 central line-days

$=\frac{\text { Number of central line-associated BSI }}{\text { Number of central line-days }} \times 1000$

\section{Calculation of DU ratio}

Steps 1, 2, and 4. Same as device-associated infection rates plus determine the number of patient-days, which is used as the denominator of the DU ratio. Patient-days are the total number of days that patients are in the location during the selected time period.

Example: Ten patients were in the unit on the first day of the month; 12 on day $2 ; 11$ on day $3 ; 13$ on day $4 ; 10$ on day $5 ; 6$ on day 6 ; and 10 on day 7 ; and so on. If we counted the patients in the unit from days 1 through 7 , we would add $10+12+11+13$ $+10+6+10$ for a total of 72 patient-days for the first week of the month. If we continued for the entire month, the number of patient-days for the month is simply the sum of the daily counts.

Step 5. Calculate the DU ratio with the following formula:

DU ratio $=\frac{\text { Number of device-days }}{\text { Number of patient-days }}$

With the number of device-days and patient-days from the examples above, $\mathrm{DU}=28 / 72=0.39$ or $39 \%$ of patient-days were also central line-days for the first week of the month.

Step 6. Examine the size of the denominator for your hospital's rate or ratio. Rates or ratios may not be good estimates of the "true" rate or ratio for your hospital if the denominator is small, ie, $<50$ device-days or patient-days.

Step 7. Compare your hospital's location-specific rates or ratios with those found in the Tables of this report. Refer to Appendix B for interpretation of the percentiles of the rates/ratios.

\section{Appendix B. Interpretation of percentiles of infection rates or device utilization ratios}

Step 1. Evaluate the rate (ratio) you have calculated for your hospital and confirm that the variables in the rate (both numerator and denominator) are identical to the rates (ratios) in the Table.

Step 2. Examine the percentiles in each of the Tables and look for the 50th percentile (or median). At the 50th percentile, $50 \%$ of the hospitals have lower rates (ratios) than the median and $50 \%$ have higher rates (ratios).

Step 3. Determine whether your hospital's rate (ratio) is above or below this median.

\section{Determining whether your hospital's rate or ratio is a HIGH outlier}

Step 4. If rate or ratio is above the median, determine whether the rate (ratio) is above the 75 th percentile. At the 75 th percentile, $75 \%$ of the hospitals had lower rates (ratios) and $25 \%$ of the hospital had higher rates (ratios).

Step 5. If the rate (ratio) is above the 75th percentile, determine whether it is above the 90th percentile. If 
it is, then the rate (ratio) is a high outlier, which may indicate a problem.

\section{Determining whether your hospital's rate or ratio is a LOW outlier}

Step 6. If rate or ratio is below the median, determine whether the rate (ratio) is below the 25 th percentile. At the 25th percentile, $25 \%$ of the hospitals had lower rates (ratios) and $75 \%$ of the hospitals had higher rates (ratios).

Step 7. If the rate (ratio) is below the 25 th percentile, determine whether it is below the 10th percentile. If the rate is, then it is a low outlier, which may be due to underreporting of infections. If the ratio is below the 10th percentile, it is a low outlier and may be due to infrequent and/or short duration of device use.

Note: Device-associated infection rates and device utilization ratios should be examined together so that preventive measures may be appropriately targeted. For example, you find that the ventilator-associated pneumonia rate for a certain type of ICU is consistently above the 90th percentile and the ventilator utilization ratio is routinely between the 75 th and 90th percentile. Because the ventilator is a significant risk factor for pneumonia, you may want to target your efforts on reducing the use of ventilators or limiting the duration with which they are used on patients to lower the ventilator-associated pneumonia rate in the unit. 